\title{
PLURALITAS DAN KONSEP PENGAKUAN INTERSUBJEKTIF DALAM PEMIKIRAN AXEL HONNETH
}

\author{
Otto Gusti Madung*
}

\begin{abstract}
Abstrak: Pemisahan antara ruang privat dan publik merupakan solusi liberalisme atas tantangan pluralitas masyarakat modern. Dalam kaca mata politik pengakuan, solusi liberalisme tidak mencukupi. Liberalisme dianggap mengenal individu hanya sebagai subjek hukum dan karena itu hanya dapat memperhatikan tuntutan validitas hukum. Dalam kaca mata liberalisme, kesetaraan subjek-subjek hukum hanya dapat dijamin jika aspek-aspek tradisi, kultural dan konsep hidup baik dijauhkan dari politik. Namun apa yang menjadi objek pengakuan justru aspek-aspek ini. Tulisan ini memperkenalkan konsep-konsep pengakuan intersubjektif Axel Honneth. Konsep pengakuan intersubjektif melampaui paham pengakuan interkultural seperti diperkenalkan oleh tokoh seperti Charles Taylor. Dalam paradigma intersubjektif, pengakuan tidak hanya dilihat pada tataran relasi interkultural, tapi dipahami sebagai sebuah antropologi. Pengakuan mengkonstruksi manusia sebagai subjek. Hal ini ditunjukkan Honneth dalam uraiannya tentang pelbagai tingkatan interaksi antarmanusia yakni tataran cinta, hukum dan solidaritas. Pada bagian akhir tulisan diajukan beberapa pertimbangan kritis atas konsep pengakuan Honneth ini.
\end{abstract}

Kata-kata Kunci: Pengakuan, multikulturalisme, intersubjektivitas, teleologi, autentisitas.

Abstract: The separation between private and public spheres is the solution of liberalism to the challenges of plurality in modern societies. In the perspective of politics of recognition this solution of liberalism is insufficient. Liberalism is considered to recognize the individual only as a subject of law and therefore can only attend to the demands of legal validity. In the perspective of liberalism, equality of legal subjects can

* Otto Gusti Madung. Sekolah Tinggi Filsafat Katolik Ledalero, Maumere 86122, Flores, NTT. E-mail:ottomadung@hotmail.com. 
only be guaranteed if the aspects of tradition, culture and the concept of a good life are seperated from politics. But precisely these aspects are the object of recognition. This paper introduces the concept of intersubjective recognition of Axel Honneth. The concept of intersubjective recognition goes beyond intercultural recognition as introduced by Charles Taylor, for example. In the intersubjective paradigm, recognition is not only seen at the level of intercultural relations, but understood as an anthropology. Recognition constructs the human being as subject. This is shown by Honneth in his account of the various levels of human interaction, that is the level of love, law and solidarity. At the end of the article the author will give some critical considerations on Honneth's concept of recognition.

Keywords: Recognition, multiculturalism, intersubjectivity, teleology, authenticity.

\section{PENDAHULUAN}

Pluralitas merupakan ciri khas yang mewarnai kehidupan bersama setiap masyarakat modern. Hal ini terungkap dalam kebinekaan pandangan, nilai, ideologi dan tradisi kultural. Di kota-kota besar kita sering jumpai kelompok-kelompok penggemar Mozart dan Lady Gaga, kaum vegetarian dan pemakan daging, neokonservatif dan pencinta lingkungan hidup, progresif dan skeptik terhadap kemajuan, kelompok Katolik, Kristen, Muslim, Hindu, Budha dan esoterik. Kebinekaan ini tidak hanya mewarnai ruang publik, tapi juga menyusup hingga ke ranah privat. Kelompok-kelompok ini hidup berdampingan dan setara. Tak ada yang dipandang lebih penting dari yang lain.

Pertanyaan fundamental yang harus dijawab oleh setiap masyarakat plural ialah seberapa plural kondisi sosial yang dapat ditoleransi sebuah masyarakat agar masyarakat tersebut tetap bertahan hidup. Apakah sebuah masyarakat plural tetap membutuhkan basis normatif kolektif? Pertanyaan ini muncul seiring dengan krisis yang melanda demokrasi modern yang dipandang sudah terlalu liberal. Untuk menjawabi krisis tersebut pluralitas nilai, ideologi dan tradisi dalam demokrasi harus dijangkarkan kembali pada nilai budaya kolektif. Politik pengakuan lahir 
sebagai jawaban atas krisis yang dihadapi konsep politik liberal yang dipandang sangat proseduralistis. Dalam liberalisme hal-hal substansial seperti kekhasan budaya digeser ke ruang privat. Dalam politik pengakuan seperti diperkenalkan oleh Charles Taylor, misalnya, kekhasankekhasan kultural tersebut justru diangkat ke ranah politik. Pengakuan tidak hanya diberikan kepada yang umum seperti pengakuan akan martabat manusia dalam liberalisme, tapi juga pada yang khas seperti kekhasan budaya kelompok kulit hitam, para lesbian, gay dan kelompokkelompok khusus lainnya.

Tulisan ini tidak saja berhenti pada paradigma pengakuan interkultural Taylorian, tapi coba melampauinya dengan memperkenalkan konsep pengakuan intersubjektif Axel Honneth. Menurut Honneth pengakuan tidak saja terjadi pada tataran relasi interkultural, melainkan menukik hingga ke ranah antropologis. Itu berarti bahwa lewat proses pengakuan intersubjektif manusia mengkonstruksikan dirinya sebagai subjek. Proses konstruksi subjek tersebut terjadi pada tiga tingkatan berbeda yakni ranah cinta, hukum dan solidaritas. Ranah cinta mengungkapkan relasi primer dan personal antarmanusia. Sementara cinta berkaitan erat dengan struktur dasar antropologis yang dialami manusia sejak ia dilahirkan ke tengah dunia, hukum berbicara tentang ikhtiar historis di mana kita dapat membaca sejarah sebuah kemajuan moralitas. Seperti sudah dijelaskan, cinta berkaitan dengan relasi intim dan hukum berbicara tentang bentuk-bentuk anonim pengakuan. Model ketiga yakni solidaritas menyangkut pengakuan nilai sosial seorang pribadi dalam konteks sebuah komunitas nilai. Berbeda dengan hukum, solidaritas bukan lagi ciri-ciri bersama yang menjadi alasan pengakuan, tapi ciri khusus yang menggambarkan prestasi atau kemampuan seorang pribadi. Dalam rangka relasi pengakuan timbal-balik terimplisit bahwa kriteria yang berpengaruh pada penghargaan nilai harus ditopang atau didukung oleh semua. Karena itu, solidaritas tidak berhubungan dengan penghargaan terhadap satu prestasi singular, melainkan nilai-nilai dan tujuan-tujuan etis dalam rangka sebuah horizon nilai bersama. Nilai sosial menggantikan pengertian status dalam masyarakat hirarkis tra- 
disional. Saya hanya dapat melihat diri sebagai subjek hukum jika saya lebih dahulu sudah mengakui yang lain sebagai pemangku hak. Dalam pandangan Kant tentang pendasaran hukum, usaha ini berkorelasi dengan sikap respek (Achtung) yang oleh Honneth diinterpretasi sebagai kontribusi bagi relasi terhadap diri yang paripurna. Respek terhadap diri tersembul dari pengalaman diakui sebagai subjek hukum yang setara dengan yang lain dalam sebuah komunitas hukum.

Uraian tentang konsep pengakuan Honneth akan didahului dengan sebuah gambaran umum tentang konsep pengakuan dan multikulturalisme. Gambaran umum ini penting guna menghantar pembaca pada uraian lebih rinci tentang konsep pengakuan intersubjektif Axel Honneth. Dibandingkan dengan model-model pengakuan lainnya seperti konsep pengakuan interkultural, pandangan Axel Honneth lebih tajam karena menggambarkan pengakuan sebagai basis antropologis pembentukan subjek. Tak ada subjek tanpa proses pengakuan, demikian pandangan Honneth. Formasi subjek lewat proses pengakuan, demikian Honneth, terjadi pada tiga tingkatan yakni pada ranah cinta, hukum dan solidaritas. Cinta adalah ungkapan relasi intim antarmanusia dan lewat cinta individu dibantu untuk mengembangkan rasa percaya diri. Hukum membantu individu untuk mengembangkan sikap respek terhadap dirinya sendiri, sedangkan solidaritas membentuk sikap penghargaan terhadap diri sebagai bagian dari sebuah komunitas nilai kolektif. Pada bagian terakhir akan diajukan sejumlah catatan kritis atas konsep pengakuan Honneth yang dirumuskan di bawah judul kognitivisme, autentisitas dan teleologi.

\section{PENGAKUAN DAN MULTIKULTURALISME}

Politik pengakuan merupakan sebuah design politik yang berakar dan berkembang dalam wacana seputar multikulturalisme. Seperti halnya liberalisme, politik pengakuan menggarisbawahi pentingnya hak atas penghargaan yang sama terhadap pelbagai konsep hidup baik yang membentuk identitas manusia dan tuntutan kesetaraan semua budaya. Selain itu, politik pengakuan mempromosikan dan mengakui kekhasan 
setiap model budaya dan tradisi. ${ }^{1}$ Konsep pengakuan bertolak dari tesis dasar bahwa identitas manusia terbentuk dari pengakuan atau tak adanya pengakuan serta pengakuan yang keliru dari yang lain. Absennya pengakuan atau pengakuan yang keliru dapat mendatangkan patologi sosial atau penderitaan bagi individu atau kelompok lain. Tiadanya pengakuan dapat berakibat pada bentuk-bentuk penindasan atau eksistensi deformatif yang palsu. ${ }^{2}$ Patologi sosial ini menjadi salah satu alasan yang mendorong munculnya diskursus seputar multikulturalisme .

Istilah "multikulturalisme" sendiri pertama kali diperkenalkan oleh sekelompok peneliti dari Chicago bernama Chicago Cultural Studies Group sebagai antitesis terhadap strategi liberal tradisional dalam menghadapi diferensiasi sosial. ${ }^{3}$ Liberalisme tradisional berpandangan bahwa perbedaan-perbedaan kultural dalam sebuah masyarakat yang ditata menurut hukum demokratis liberal yang mengatur politik, ekonomi dan kehidupan sosiokultural berdasarkan prinsip-prinsip universal, merupakan bagian dari ranah privat dan tidak relevan secara publik. Politik multikulturalisme menentang model liberalisme seperti ini. Cita-cita dasar multikulturalisme ialah menjawab pertanyaan tentang bagaimana menata kehidupan bersama yang setara, damai dan dalam suasana saling pengakuan dalam sebuah masyarakat yang plural secara etnis, rasial, kultural dan religius tanpa adanya rujukan normatif bersama.

Secara umum dikenal dua model multikulturalisme. Pertama, multikulturalisme liberal memperjuangkan penghapusan bentuk-bentuk diskriminasi hukum, politik dan sosial serta mendukung perjuangan kelompok-kelompok tersebut dalam melestarikan identitas kulturalnya. Multukulturalisme liberal juga tetap menekankan pentingnya budaya

1 Bdk. Dieter Nohlen und Reiner-Olaf Schultze, Lexikon der Politikwissenschaft. Theorien, Methode, Begriffe, Bd. I: A-M (München: Verlag C.H. Beck, 2002), S. 21.

2 Bdk. Charles Taylor, "Die Politik der Anerkennung," in Multikulturalismus und die Politik der Anerkennung, hrsg. v. Charles Taylor (Frankfurt am Main: Suhrkamp, 2009), SS. 11-66.

3 Bdk. Radostin Kaloianov, "Multikulturalismus und Kritik," Polylog. Zeitschrift für interkulturelles Philosophieren 24, (Januar 2010): 82 (81-97). 
politik kolektif yang menjamin kesatuan sosial. Di samping itu, multikulturalisme liberal hanya legitim sejauh tidak bertentangan dengan prinsip kesejahteraan individu dan karena itu berpijak pada paham hakhak asasi manusia dan hak-hak konstitusional. Kedua, multikulturalisme radikal menekankan makna eksistensial dari masing-masing identitas kolektif yang berbeda. Multikulturalisme radikal ingin menyelamatkan masa depan kelompok-kelompok budaya khusus dari ancaman kepunahan dan menuntut pengakuan atas hak-hak khusus kelompokkelompok kultural tersebut di ruang publik hingga membuka ruang bagi pelaksanaan referendum.

Politik multikulturalisme memiliki sejumlah peluang dan juga bahaya untuk kohesi sosial dalam sebuah negara. Hal ini dapat dijumpai di Kanada misalnya. Undang-undang antidiskriminasi dan tuntutan akan kesempatan yang sama bagi semua individu merupakan instrumen politik penting dalam cita-cita multikulturalisme. Steven Vertovec dan Susanne Wesendorf mengidentifikasi lima dimensi penggunaan konsep multikulturalisme:

Multiculturalism can variously be understood as I) a way of describing the actual makeup of a society; II) a general vision of the way government and society should orient itself; III) a specific set of policy tools for accammodating minority cultural practices; IV) specially created framework of governance allowing for the representation of immigrant and ethnic minority interests; and V) a variety of support mechanisms and funds for assisting ethnic minority communities to celebrate and reproduce their tradition. ${ }^{4}$

Kelima aspek ini dirumuskan oleh Will Kymlicka dan Bauböck dalam definisi tentang konsep multikulturalisme:

Liberal multiculturalism is the view that states should not only uphold the familiar set of common civil, political, and social rights of citizenship that are protected in all constitusional liberal democracies, but also adopt various group-

4 Steven Vertovec and Susanne Wesendorf, Migration and Cultural, Religious and Linguistic Diversity in Europe: An overview of Issues and Trends. Centre on Migration, Policy and Society, Working Paper No. 18, University of Oxford (2005), p. 3 ff. 
specific rights or policies that are intended to recognize and accommodate the distinctive identities and aspirations of ethnocultural groups. ${ }^{5}$

Sementara itu Bauböck mendefinisikan multikulturalisme sebagai berikut: "Multiculturalism regards the coexistence of distinct cultural groups in a society as a positive value that should be supported by public policies." 6

Ketiga definisi di atas menekankan aspek politis multikulturalisme. Ini bertentangan dengan sejumlah pendapat yang mengatakan bahwa multikulturalisme tak lebih dari sebuah ilusi teoretis tanpa relevansi politis. Apa itu politik multikulturalisme? Politik multikulturalisme dipahami sebagai politik yang coba menerjemahkan faktum multikulturalitas sosial ke sebuah tatanan dan kondisi politik institusional. Politik multikulturalisme sangat penting dijalankan sebab dalam kondisi sosial, politik, ekonomi dan kultural masyarakat modern dan postmodern, elemenelemen reproduksi sosial yang penting seperti identitas kelompok, bahasa, budaya yang hanya dapat bertahan dalam dimensi publik membutuhkan jaminan dan dukungan politik negara. ${ }^{7}$

Politik multikulturalisme memiliki tiga dimensi penting yakni aspek epistemologis, normatif dan politik-praktis. Pada tataran logis-epistemologis multikulturalisme dibedakan ke dalam dua model yakni multikulturalisme pluralistis dan multikulturalisme kosmopolitis. Pluralisme merancang sebuah epistemologi politik yang berorientasi pada kelompok kolektif, berangkat dari budaya dominan (Leitkultur) yang mentoleransi semua yang lain, menekankan batas-batas antarkelompok. Kosmopolitisme menganalisis kebinekaan masyarakat dari sudut pandang individu, menunjukkan keterbukaan terhadap semua kelompok dan budaya serta merayakan keanggotaan individu pada kelompok-kelompok yang ber-

5 Will Kymlicka, Multicultural Odysseys: Navigating the New International Politics of Diversity (Oxford: University Press, 2007), p. 61.

6 Rainer Bauböck, "Multiculturalism," in Routledge Encyclopedia of Social Theory, ed. Austin Harrington, Barbara Marshal, Hans-Peter Müller (London/New York: Routledge, 2006), p. 382 (382-384).

7 Bdk. ibid., hlm. 83. 
beda. ${ }^{8}$ Aspek normatif multikulturalisme coba menjawab pertanyaan mengapa faktum multikulturalitas sosial harus ditransformasi menjadi multikulturalisme politis. Jawaban atas pertanyaan ini dijelaskan dalam perdebatan antara liberalisme dan komunitarisme. Multikulturalisme liberal berpandangan bahwa kebudayaan atau identitas harus dilindungi secara politis karena kebudayaan menciptakan syarat penting untuk penghormatan terhadap diri dan otonomi. ${ }^{9}$ Dari sudut pandang komunitarisme, multikulturalisme harus dipertahankan karena nilai intrinsik yang dimiliki setiap kebudayaan untuk integritas personal, pembentukan identitas, konstruksi makna dan pandangan tentang dunia.

\section{KONSEP PENGAKUAN INTERSUBJEKTIF AXEL HONNETH}

Pada bagian terdahulu kita telah melihat bahwa teori pengakuan pada umumnya lahir sebagai catatan kritis atas kegagalan praktik politik liberal. Liberalisme dianggap mengenal individu hanya sebagai subjek hukum dan karena itu hanya dapat memperhatikan tuntutan validitas hukum. Dalam kaca mata liberalisme, kesetaraan subjek-subjek hukum hanya dapat dijamin jika aspek-aspek tradisi, kultural dan konsep hidup baik dijauhkan dari politik. Namun apa yang menjadi objek pengakuan justru aspek-aspek ini, hal-hal yang menempatkan individu dalam konteks nilai bersama yang dimaknai secara kolektif. Charles Taylor berpandangan bahwa model liberalisme yang sensibel terhadap diferensiasi harus mengkompensasi pemiskinan individualistis (individualistische Verarmung) tersebut dan memperluas horison liberalisme dengan memberikan perhatian khusus pada hak-hak kultural (kolektif).

Tuntutan yang sama juga dimiliki paradigma pengakuan intersubjektif yakni menutup lubang yang ditinggalkan oleh liberalisme. Dalam bahasa Hegelian, politik tidak cukup hanya memperhatikan

8 Bdk. David Hollinger, Postethnic America: Beyond Multiculturalism (New York: Basic Books, 2006), p. 85.

9 Bdk Jeff Spinner-Halev, "Multiculturalism and Its Critics," in The Oxford Handbook of Political Theory, ed. John. S. Dryzek et al. (Oxford: Oxford University Press, 2008), p. 567 (546-564). 
subjek hukum, tapi seluruh pribadi (persona) manusia. Paradigma ini bertolak dari kritik Hegel atas formalisme filsafat moral dan hukum Kantian. Dalam konsep moral dan hukumnya Kant secara sistematis mengabaikan moral substantif yang dihayati setiap kebudayaan atau Sittlichkeit yang menjadi awal dari norma-norma yang dirumuskan secara formal. Kita tidak memiliki padanan bahasa Indonesia yang tepat untuk term Sittlichkeit ini. Franz Magnis-Suseno mengartikannya sebagai "tatanan sosial-moral yang terwujud dalam lembaga-lembaga kehidupan kemasyarakatan manusia" (termasuk adat-istiadat). ${ }^{10}$ Axel Honneth mencoba mengatasi proses pemiskinan formalistis (formalistische Verarmung) ini. Ia menolak tesis Taylor tentang reparasi historis identitas individual dan kolektif lewat pengakuan. Dengan ini Honneth melampaui tuntutan teoretis Taylor. Teori pengakuan Honneth merupakan sebuah teori sosial normatif substantif yang harus mampu menjelaskan kemajuan moral dan hukum sekaligus. ${ }^{11} \mathrm{Hal}$ ini akan ditunjukkan dalam uraian berikut tentang tiga jenis ranah interaksi manusia.

\section{TRILOGI RANAH INTERAKSI}

Ikhtiar teoretis Honneth merujuk pada dua pemikir penting yakni Hegel dan Mead. Dari konsep Sittlichkeit Hegel muda Honneth mendapatkan percikan pencerahan bahwa formasi identitas manusia tak mungkin terwujud tanpa pengakuan intersubjektif. Dari psikologi sosial Mead, Honneth mengambil alih konsep realisasi postmetafisik dan materialistis proses formasi diri. ${ }^{12}$ Pergumulan dengan kedua pemikir ini menghasilkan struktur dasar pengakuan intersubjektif yang menjadi syarat formasi identitas. Hal ini dirumuskan oleh Honneth sebagai berikut: "Reproduksi kehidupan sosial terjadi di bawah imperatif pengakuan timbal-balik, sebab subjek-subjek hanya mampu menggapai

10 Franz Magnis-Suseno, Pijar-Pijar Filsafat (Yogyakarta: Kanisius, 2005), hlm. 87.

11 Bdk. Axel Honneth, Kampfum Anerkennung. Zur moralischen Grammatik sozialer Konflikte (Frankfurt am Main: Suhrkamp, 1994), S. 148.

12 Bdk. Axel Honneth, Unsichtbarkeit. Stationen einer Theorie der Intersubjektivität (Frankfurt am Main: Suhrkamp, 2003). 
10 Pluralitas dan Konsep Pengakuan Intersubjektifdalam Pemikiran Axel Honneth (Otto Gusti Madung)

pemahaman diri yang praktis (etis) jika belajar melihat diri mereka dari sudut pandang normatif partner interaksi sebagai tujuan relasi sosial."13

Struktur dasar ini mendapat artikulasinya dalam tiga ranah interaksi berbeda. Dalam setiap ranah terjadi proses pengakuan timbal-balik yang membantu individu dalam mengembangkan relasi dengan dirinya. Cinta mengungkapkan relasi intim manusia dan membantu individu untuk mengembangkan rasa percaya diri. Hukum membantu membentuk rasa respek terhadap diri dan solidaritas membantu penghargaan terhadap diri sebagai bagian dari sebuah komunitas nilai kolektif.

Cinta, relasi intim primer seperti hubungan cinta suami istri, persahabatan atau relasi orang tua-anak menunjukkan kekhasan di mana subjek mengekspresikan diri lewat kebutuhan dan saling memberikan pengakuan. Melampaui rumusan formal Hegel tentang cinta sebagai "menjadi diri sendiri dalam yang lain atau yang asing" (Seinselbstsein in einem Fremden), ${ }^{14}$ Honneth merujuk pada pandangan-pandangan psikologi relasi objek. Jika model libido Freudian melihat suasana psikologi masa kanak-kanak sebagai medan pergolakan antara tekanan libido dan kontrol diri, perkembangan lanjut teori relasi objek dari psikoanalisis menafsir pengamatan bahwa aku yang berada dalam proses menjadi matang dalam pengalaman interaksi prabahasa berkembang antara ikatan emosional dan ketakutan akan kehilangan ikatan tersebut. Tahap pertama dari intersubjektivitas yang tak terdiferensiasi (undifferenzierte Intersubjektivität) atau yang dikenal dengan simbiose perlahan-lahan bertumbuh menjadi pribadi otonom. ${ }^{15}$ Seorang anak kecil sangat bergantung pada orang lain, sehingga relasinya dengan lingkungan sekitar tidak punya jarak. Ia mengalami lingkungan dan yang lain sebagai sebuah kesatuan dengan dirinya. Karena itu ketergantungan anak pada ibunya bukan sebuah mimpi buruk, tapi titik tolak sebelum menciptakan

13 Axel Honneth, Kampf um, op.cit., S. 148.

14 Georg Wilhelm Friedrich Hegel, System der Sittlichkeit (Hamburg: Meiner Verlag,1967), S. 17.

15 Bdk. Axel Honneth, Kampf um, op.cit., S. 158. 
jarak dengan yang lain dalam proses sosialisasi. Seorang anak kecil tidak saja dalam arti empiris bergantung pada pemenuhan kebutuhan oleh orang dekatnya, tapi juga pengalaman akan diri dan dunianya menyatu dengan orang terdekatnya. ${ }^{16}$ Anak kecil tentu saja belum mampu memahami dunia objek-objek secara kognitif sebab pemahaman seperti itu mengandaikan kemampuan menciptakan distingsi dan jarak. Hubungan simbiosis ini menjadi sempurna dengan adanya ketergantungan sang ibu pada anaknya. Memang dibandingkan dengan anak, ibu memiliki sarana komunikasi untuk mengartikulasikan kebutuhannya. Namun karena anak tidak mampu berkomunikasi secara verbal, ibu harus mengidentifikasikan diri dengan anak agar bisa memahaminya.

Ketergantungan timbal-balik antara ibu dan anak akan berakhir ketika keduanya mencapai tingkatan otonomi tertentu. Ibu mulai mengambil jarak dari anak agar bisa bertumbuh menjadi makhluk yang mandiri. Ketidakhadiran ibu berfungsi sebagai ujian kemampuan untuk menunda pemenuhan kebutuhan secara langsung dan bertahan dalam ketidakhadiran orang terdekat. Hal ini penting agar hubungan simbiosis tidak menjadi sesuatu yang patologis dalam kehidupan sosial ketika anak bertumbuh dewasa. ${ }^{17}$ Jika seluruh perkembangan berjalan normal, maka akan terjadi pergeseran dari intersubjektivitas simbiosis yang tidak terdiferensiasi menuju "intersubjektivitas yang dirasakan" (gefühlte Intersubjektivität $)^{18}$ yang membantu mengatasi perpisahan dari orang dekat dan menciptakan rasa percaya terhadap ikatan intersubjektivitas itu sendiri. Pada tahap ini bukan lagi pemuasan naluri secara langsung yang menghilangkan dahaga, sebab dalam cinta orang bisa menahan rasa dahaga itu seorang diri. Dengan demikian rasa percaya pun bertumbuh bahwa kasih sayang dan pelayanan bisa saja terjadi kendati pemberian langsung tidak lagi terjadi. Pengalaman ini memberi nilai tambah bagi pribadi yang sedang dalam proses menjadi. Ia merasa pasti dengan cinta

16 Bdk. Axel Honneth, Unsichtbarkeit, op.cit., S. 150 ff.

17 Bdk. Axel Honneth, Kampf um, op.cit., S. 171.

18 Ibid., S. 167. 
12 Pluralitas dan Konsep Pengakuan Intersubjektifdalam Pemikiran Axel Honneth (Otto Gusti Madung)

yang dialami, rasa percaya pun bertumbuh yang mengusir rasa takut dalam kesendirian.

Dari teori relasi objek Honneth mencoba menyusun sebuah hipotese relasi cinta. Menurut Honneth, relasi cinta didorong oleh kerinduan akan relasi simbiosis primordial yang terjadi pada fase pertama relasi anak dan ibu. Kesatuan tanpa jarak kritis dalam relasi ini berpengaruh sangat mendalam dalam ekonomi psikis sehingga dialami sebagai gambaran ideal sebuah pembauran yang membahagiakan. Namun karena dalam kehidupan orang dewasa kesatuan itu tidak mungkin terwujud, maka cinta hanya mungkin sebagai jembatan antara relasi simbiosis dengan perpisahan. Hanya sebuah "simbiosis yang rapuh" (zerbrochene Symbiose) $)^{19}$ mampu memadukan ideal kesatuan dengan pengakuan akan yang lain sebagai pribadi yang otonom. Dengan demikian modus pengakuan cinta tidak terletak pada sebuah kondisi intersubjektif, melainkan dalam busur ketegangan komunikatif yang secara terus-menerus menjembatani pengalaman kesendirian (Erfahrung des Alleinseinskönnens) dengan pembauran (Verschmolzensein). ${ }^{20}$ Cinta sebagai absennya pembatas (Entgrenzung) terungkap dalam pengalaman bersama tanpa pamrih di antara sahabat atau dalam hubungan seksual ekstatis. Namun pengalaman ini tidak bertahan untuk jangka waktu lama. Pengalaman-pengalaman ini merupakan fenomen batas yang menandai satu kutup dinamik relasi-relasi primer. Kutub lainnya yakni perpisahan yang niscaya terjadi merupakan prasyarat untuk dapat mengalami momen-momen persatuan sebagai sesuatu yang ideal. Karena itu cinta bukan kondisi, tapi dinamika yang hidup dari ketegangan antara kesatuan dan jarak. Honneth menekankan bahwa relasi-relasi primer selalu berkaitan dengan dasar kepastian emosional yang memberikan alasan cukup untuk secara logis dan genetis menempatkan modus pengakuan cinta sebagai yang primer di hadapan dua modus yang lainnya. ${ }^{21}$

19 Ibid., S. 169

20 Bdk. ibid., S. 170

21 Bdk. ibid., S. 171 
Hukum, satu-satunya yang menghubungkan cinta dan relasi hukum adalah analogi struktural dalam mengungkapkan diri lewat modus pengakuan timbal-balik. Itu berarti bahwa proses transposisi etika konfensional (Sittlichkeit) menjadi proposisi-proposisi hukum universal tidak dikisahkan sebagai sejarah terpisah tentang perkembangan proses kodifikasi norma-norma modern, melainkan bagian dari sejarah yang ditempatkan dalam keseluruhan dinamika pengakuan. Jika cinta berhubungan dengan struktur dasar antropologis, maka hukum berbicara tentang ikhtiar historis di mana kita dapat membaca sejarah sebuah kemajuan moralitas. Saya hanya dapat melihat diri sebagai subjek hukum jika saya lebih dahulu sudah mengakui yang lain sebagai pemangku hak. Untuk menjelaskan posisinya Honneth merujuk pada Immanuel Kant. Menurut pandangan Kant tentang pendasaran hukum, usaha ini berkorelasi dengan sikap respek (Achtung). Namun Honneth menginterpretasi konsep Achtung sebagai kontribusi bagi relasi terhadap diri yang paripurna. Respek terhadap diri tersembul dari pengalaman diakui sebagai subjek hukum yang setara dengan yang lain dalam sebuah komunitas hukum.

Kant memperkenalkan konsep respek (Achtung) ketika hukum moralnya bersentuhan dengan persoalan motivasi. Jika dalam kaca mata imperatif kategoris saya sudah mengetahui bahwa maksim sebuah tindakan dapat diuniversalisasi, maka dengan pasti saya juga tahu jika tindakan itu wajib secara moral. Namun pertanyaan yang belum terjawab ialah, mengapa saya harus bertindak menurut maksim tersebut? Jurang yang terbentang antara pemahaman moral dan motivasi tindakan kini harus dijembatani dengan konsep Achtung (respek). Konsep respek menghadapi tugas yang sulit sebab Kant dalam distingsi kategoris antara dunia noumenal hukum moral dan dunia fenomenal dorongan indrawi serta kepentingan empiris menemukan prasyarat yang mampu menjamin kewajiban yang niscaya dari imperatif kategoris. ${ }^{22}$ Syarat

22 Bdk. Heiner F. Klemme, Manfred Kühn, Dieter Schönecker (Hrsg), Moralische Motivation. Kant und die Alternativen (Hamburg: Meiner Verlag, 2006). 
14 Pluralitas dan Konsep Pengakuan Intersubjektifdalam Pemikiran Axel Honneth (Otto Gusti Madung)

rasionalitas praktis Kantian justru ketakterjembataninya jurang yang harus dihubungkan oleh konsep respek. Kant pertama-tama memahami respek sebagai perasaan yang harus muncul untuk menaati hukum terlepas dari kecenderungan-kecenderungan emosional. ${ }^{23}$ Dengan menjadikan perasaan sebagai basis motivasi etis, Kant dikritik menempatkan moral hukum dan moral rasionalitasnya atas dasar moral perasaan empiris. Kant menolak kritikan tersebut. Menurutnya, respek berkaitan dengan perasaan moral yang digerakkan oleh akal budi. ${ }^{24}$ Untuk memahami apa itu perasaan bukan dalam pengertian afektif tapi rasional, kita harus kembali kepada penjelasan Kant tentang perasaan moral. Konsep perasaan dalam uraian Kant muncul pada bagian di mana kewajiban "sebagai keniscayaan sebuah tindakan dari rasa respek terhadap hukum" 25 sudah terstruktur secara objektif dan kemudian masih harus diperkuat dengan motivasi subjektif. Maka Kant mendefinisikan perasaan respek sebagai "ketaatan kehendak di bawah hukum," 26 jadi pengalaman bahwa kehendakku diarahkan secara moral, bukannya didorong oleh kepentingan, nafsu, keinginan atau rasa takut. Respek berkaitan erat dengan perasaan yang mengarahkan pengetahuan akan refleksi moral. $^{27}$

Kita perlu menguraikan konsep respek Kantian di sini secara detail karena fungsinya sebagai landasan validitas hukum. Dalam kaitan dengan pengakuan hukum Kant membuat rumusan yang sangat jelas: "Segala bentuk penghargaan atau respek terhadap seorang pribadi sesungguhnya merupakan penghargaan terhadap undang-undang semata-mata." ${ }^{28}$ Perbedaan dengan teori pengakuan menjadi jelas jika kita

23 Bdk. Immanuel Kant, Grundlegung zur Metaphysik der Sitten, hrsg. v. Karl Vorländer (Hamburg: Meiner Verlag, 1994), AA IV 400.

24 Bdk. Immanuel Kant, Kritik der praktischen Vernunft, hrsg. v. Karl Vorländer (Hamburg: Meiner Verlag, 1990), AA V 75-76.

25 Immanuel Kant, Grundlegung, op.cit., AA IV 400.

26 Ibid., AA IV 401.

27 Bdk. Immanuel Kant, Kritik der praktischen, AA V 79.

28 Immanuel Kant, Grundlegung zur, AA IV 401. 
memperhatikan secara khusus pengaruh respek terhadap diri. Bagi Kant, penghormatan terhadap hukum moral berdampak pada penghargaan terhadap diri yang berpijak pada prinsip kemanusiaan dalam persona. ${ }^{29}$ Hormat terhadap diri sendiri bertolak dari kebebasan untuk menempatkan diri di bawah imperatif hukum moral. Hormat terhadap diri sendiri bukan kewajiban, melainkan prasyarat kemungkinan satu-satunya untuk berpikir tentang kewajiban. ${ }^{30}$ Barangsiapa tidak menghargai kemanusiaan dalam dirinya, tidak mungkin dapat menjadi manusia bermoral. Kant mendefinisikan kemanusiaan sebagai martabat, maka secara analogis berlaku prinsip pengakuan terhadap yang lain sebagai pribadi yang harus dihormati. Pengakuan timbal balik menurut Kant hanya mungkin terjadi lewat undang-undang. ${ }^{31}$

Penulis berpandangan bahwa Honneth di sini sependapat dengan konsep Kantian tentang penghormatan terhadap diri sendiri (Selbstachtung) ketika ia mengadopsi struktur universal hukum berdasarkan prinsip pengakuan timbal-balik sebagai pemangku hak. Objek dari penghormatan tersebut adalah otonomi dalam pengertian kemampuan untuk menjadi sumber tindakan moral: "Karena legitimasi komunitas hukum modern hanya bergantung pada ide tentang konsensus rasional individuindividu setara, maka setiap komunitas hukum tersebut didasarkan pada pandangan tentang tanggungjawab moral setiap anggotanya." 32 Sebuah ruang hukum, di mana saya dapat muncul sebagai subjek hukum, hanya terbentuk jika saya mengakui semua yang lain sebagai makhluk otonom. Jika tidak demikian, maka validitas universal hukum akan kehilangan basis legitimasinya dan hukum bukan hukum lagi. Hukum itu atau bersifat universal atau bukan hukum. Pengakuan yang total terhadap manusia sebagai pribadi otonom hanya mencapai tingkat kematangan jika

29 Bdk. Volker Gerhard, "Menschheit in meiner Person. Expose zu einer Theorie exemplariischen Handelns," Jb Recht Ethik 14 (2006), SS. 215-224.

30 Bdk. Immanuel Kant, Metaphysik der Sitten, hrsg. v. Bernd Ludwig (Hamburg: Meiner Verlag, 1990), AA VI 402 ff.

31 Bdk. ibid, AA VI 462.

32 Axel Honneth, Kampf um, S. 184 ff. 
16 Pluralitas dan Konsep Pengakuan Intersubjektif dalam Pemikiran Axel Honneth (Otto Gusti Madung) individu bersangkutan tidak lagi terikat pada status sosial, milik, kelas sosial atau jenis kelamin, tapi sungguh diakui sebagai persona dengan status otonom. ${ }^{33}$ Konsep otonomi mengalami perkembangan dan kemajuan lebih luas. Hal ini secara empiris ditunjukkan lewat evolusi konsep hak kebebasan individual menuju hak partisipasi politik hingga terbangunnya hak-hak kesejahteraan sosial sebagai jaminan syaratsyarat empiris otonomi individu. Apakah arti prinsip otonomi secara empiris dan melampaui argumetasi transendental Kantian, dapat dipantau dalam sejarah kemajuan hukum yang memberi landasan empiris bagi sayarat-syarat kemungkinan otonomi.

Sejarah kemajuan hukum seperti dikemukakan Honneth dinilai terlalu optimistis. Pandangan teleologis seperti ini sudah banyak mendapat kritikan antara lain dari Adorno, Horkheimer dan juga Michel Foucault. Diskusi tentang teleologi hukum Honneth akan dikemukakan pada bagian berikutnya. Pada bagian ini akan ditunjukkan perbedaan mendasar antara Honneth dan Kant. Seperti sudah dijelaskan, Kant tidak berbicara tentang persona empiris. Yang harus dihormati, demikian Kant, kemanusiaan dalam personaku yang mewajibkan saya untuk taat pada hukum. Juga dalam pengertian yang sama martabat dari yang lain harus dihormati karena hukum moral tersebut terungkap dalam persona yang lain. Secara transendental Kant berargumentasi bahwa respek hanya dapat menjadi pantulan subjektif dari validitas hukum objektif. Dalam perspektif historis Axel Honneth, persona memiliki sejumlah kekhasan yang menunjukkan apakah ia layak dikategorikan sebagai subjek hukum atau tidak. Jika seperti halnya Honneth sejararah hukum dipandang secara normatif, maka pemberian kriteria untuk bidang validitas hukum tak mungkin dapat terhindarkan. Diskursus tentang "kemampuan" dan "karakter" persona yang otonom dimengerti sebagai syarat-syarat yang memungkinkan terwujudnya otonomi sebagai partisipasi total dalam kehidupan politik. Secara historis terbukti bahwa jaminan hukum kebebasan individu hanya mungkin diperoleh 
lewat partisipasi politis dalam formasi kehendak publik. Di samping itu partisipasi politis tidak mungin berhasil tanpa adanya kepastian standarstandar minimal sosial dan substansial. Di sini tampak jelas bahwa seluruh proses perkembangan otonomi dipandang sebagai sesuatu yang dikendalikan oleh kerja-kerja kesadaran dalam terang deskripsi kondisi empiris. ${ }^{34} \mathrm{Hal}$ ini menempatkan pengakuan dalam konteks pengetahuan atau epistemologi. Konsep pengakuan bagi Honneth dipikirkan seturut model pemahaman kognitif realitas empiris yang kemudian diikuti dengan penilaian etis.

Solidaritas, uraian tentang trilogi model pengakuan ditutup dengan pengakuan sebagai penghargaan nilai sosial. Seperti sudah dijelaskan, cinta berkaitan dengan relasi intim dan hukum berbicara tentang bentukbentuk anonim pengakuan. Model ketiga yakni solidaritas menyangkut pengakuan nilai sosial seorang pribadi dalam konteks sebuah komunitas nilai. Berbeda dengan hukum, di sini bukan lagi ciri-ciri bersama yang menjadi alasan pengakuan, tapi ciri khusus yang menggambarkan prestasi atau kemampuan seorang pribadi. Dalam rangka relasi pengakuan timbal-balik terimplisit bahwa kriteria yang berpengaruh pada penghargaan nilai harus ditopang atau didukung oleh semua. Dengan demikian, solidaritas tidak berhubungan dengan penghargaan terhadap satu prestasi singular, melainkan nilai-nilai dan tujuan-tujuan etis dalam rangka sebuah horizon nilai bersama. Nilai sosial menggantikan pengertian status dalam masyarakat hirarkis tradisional. Perbedaan mendasar terungkap dalam keterbukaan nilai terhadap pluralitas cita-cita pribadi seperti tampak dalam masyarakat modern yang kompleks. Nilai kolektif diukur berdasarkan prestasi-prestasi tertentu yang melampaui batasbatas kelompok status. Jika aspek normatif dari status bertransformasi ke dalam bentuk hukum anonim, penilaian sosial ditentukan oleh prestasi yang dapat dihasilkan oleh masing-masing individu terlepas dari kelas sosialnya. Penilaian sosial di atas melampaui intersubjektivitas pengakuan sekian sehingga penilaian sosial tidak hanya terikat pada

34 Bdk. ibid., S. 182. 
18 Pluralitas dan Konsep Pengakuan Intersubjektif dalam Pemikiran Axel Honneth (Otto Gusti Madung) relasi timbal-balik antarindividu, tapi juga berorientasi pada sistem yang diakui secara kolektif. Nilai sosial dari kemampuan individu ditakar berdasarkan kriteria sejauh mana ia mewujudkan cita-cita masyarakat. ${ }^{35}$ Inilah simbol formal yang menjamin integrasi sosial dalam masyarakat posttradisional.

Relasi sosial timbal-balik dinilai berdasarkan kriteria konsep hidup baik. Konsep hidup baik merupakan transposisi dari term Sittlichkeit Hegelian dalam sebuah masyarakat plural. ${ }^{36}$ Seperti halnya Pierre Bourdieu, Honneth merumuskan intuisi bahwa pada lapisan-lapisan sosial tertentu simbol-simbol kultural berbeda mengumpulkan modal kultural guna membedakan diri dari yang lain. ${ }^{37}$ Namun terdapat perbedaan antara keduanya. Bourdieu meninggalkan pandangan tentang aktor yang bertindak secara ekonomis guna menyelamatkan sebuah perspektif normatif. Dalam sebuah masyarakat posttradisional, demikian Honneth, pengakuan tidak lagi diperoleh karena perasaan keanggotaan dalam sebuah masyarakat hirarkis, tapi individu sendiri mendefinisikan dirinya dalam sebuah kelompok. Honneth berbicara tentang Selbstschätzung atau penghargaan terhadap diri. ${ }^{38}$

Menurut Honneth, solidaritas terwujud dalam proses-proses sosial yang terlaksana secara kolektif yang menempatkan prestasi individual sebagai prioritas yakni pasar. Pertanyaan kritis yang muncul adalah, bagaimana mungkin Honneth melihat ekonomi yang ditata secara kapitalistis sebagai sebuah tindakan (etis)? Untuk menjawab pertanyaan ini, perlu dijelaskan apa yang dimaksudkan dengan konsep Leistung (prestasi) menurut Honneth. Bagi Honneth jelas bahwa pandangan yang mengatakan bahwa di arena pasar bebas prestasi kerja diupah secara adil tak lebih dari ideologi para pemilik modal untuk memperkuat posisinya dan mereproduksi bentuk-bentuk organisasi ekonomi. Namun prin-

35 Bdk. ibid., S. 198.

36 Bdk. ibid., S. 204.

37 Bdk. Pierre Bourdieu, Die feinen Unterschiede. Kritik der gesellschaftlichen Urteilskraft (Frankfurt am Main: Suhrkamp, 1997).

38 Bdk. Axel Honneth, Kampf um, S. 209. 
sip prestasi (Leistungsprinzip) juga berfungsi sebagai legitimasi substansial bagi ketidaksetaraan yang diciptakan oleh pasar. Akan tetapi dalam masyarakt ekonomi (bürgerliche Gesellschaft) ketidaksamaan ini hanya dibenarkan jika bukan lagi kelompok status atau kelas sosial tertentu yang menguasai resources, tapi jika kepemilikan itu merupakan hasil dari usaha kerja keras. Privilese harus didasarkan pada pendasaran rasional, dan bentuk privilese yang rasional serta diterima umum adalah penilaian atas Leistung atau prestasi kerja individual. Dalam kerangka berpikir ini, substansi rasional dari ketidaksetaraan sosial diterima jika melampaui bentuk-bentuk menipulatif empiris, prinsip yang melegitimasi ketidaksamaan itu mengandung tuntutan normatif yakni secara fair dan wajar memperhatikan prestasi individual semua warga masyarakat dalam bentuk sebuah penghargaan timbal-balik. ${ }^{39}$ Tesis ini meyakinkan Honneth untuk menafsir konflik distribusi dalam masyarakat kapitalis sebagai perjuangan untuk pengakuan (Anerkennungskämpfe). Dalam perdebatan dengan Nancy Fraser $^{40}$ menjadi jelas bahwa konsep pengakuan dalam arti yang fundamental lebih dari sebuah diskursus tentang posisi sosial kelompok-kelompok kultural.

Guna mengahadapi sejumlah pertimbangan kritis atas pandangan tentang pasar sebagai bentuk penghargaan solidaritas timbal-balik, Honneth merujuk pada konsep kemajuan moral (moralischen Fortschritt). Honneth berpandangan bahwa konsep prestasi sebagai “basis konsensus moral" 41 dapat membantu membendung kebuasan hukum rimba pasar bebas. Justru karena pasar kerja kapitalisme bukan merupakan locus solidaritas, maka perspektif normatif yang terkandung dalam konsep Leistung (prestasi) sebagai medium pengakuan mendorong dan menjaga dinamika diskusi tentang upah yang adil dalam dunia ekonomi pasar. Tanpa konsep Leistung yang dirumuskan sebagai teori pengakuan, domi-

39 Bdk. Axel Honneth, “Umverteilung als Anerkennung. Eine Erwiderung auf Nancy Fraser," in Umverteilung oder Anerkennung? Eine politisch-philosophische Kontroverse, hrsg. von Nancy Fraser und Axel Honneth (Frankfurt am Main: Suhrkamp, 2003), S. 176

40 Bdk. Ibid., S. 191 ff.

41 Ibid., S. 186. 
20 Pluralitas dan Konsep Pengakuan Intersubjektif dalam Pemikiran Axel Honneth (Otto Gusti Madung)

nasi logika ekonomi dalam semua ranah kehidupan manusia tak mungkin dapat dipatahkan.

Pertanyaan yang masih harus dijawab ialah bagaimana cara mendorong kemajuan moral. Untuk itu Honneth menambahkan uraiannya dengan komponen moral psikologis yang dalam pengalaman penistaan mengungkapkan ketiadaan pengakuan yang sesungguhnya. Penistaan (Mißachtung) merupakan "aspek dari perilaku yang merugikan di mana individu melecehkan pemahaman dirinya yang positif yang sudah dibangunnya lewat jalan-jalan intersubjektif." 42 Dengan pelecehan dan pemerkosaan terjadi ancaman atas integritas fisik, diskriminasi hukum dan eksklusi mengancam integritas sosial dan penghilangan martabat (Entwürdigung) serta penghinaan menghancurkan martabat pribadi manusia. Di sini tampak koherensi antara tiga dimensi pengakuan dan pengalaman pelanggaran atas pengakuan tersebut.

Pada Hegel dan Mead tidak ditunjukkan relasi antara pengalaman penderitaan dan tindakan-tindakan aktif. Kekurangan ini diatasi oleh Honneth dengan menjelaskan bahwa pengalaman-pengalaman penistaan mendorong terjadinya perjuangan untuk pengakuan (Kampf um Anerkennung). Pengalaman kekerasan tidak hanya dilihat sebagai pengalaman individual, tapi pengalaman kolektif. Karena itu perbaikan hanya mungkin terjadi jika terdapat perubahan secara kolektif atas syarat-syarat struktur normatif. ${ }^{43}$ Pengalaman kekerasan individual akan berubah menjadi pengalaman ketidakadilan sosial jika gangguan integritas tersebut berpijak pada sebuah praksis institusional yang telah kehilangan pesona legitimasinya. Pelecehan hak kolektif terjadi ketika norma institusional yang berpijak pada alasan-alasan rasional universal diabaikan. ${ }^{4}$ Untuk memberi pendasaran atas pergeseran paradigma normatif dari sekedar deskripsi prosedural konflik-konflik sosial, maka perlu dijelaskan apa yang menjadi dasar dari tuntutan-tuntutan tersebut. Dasarnya ialah

42 Axel Honneth, Kampf um, S. 212.

43 Carolin Emcke, Kollektive Identitäten (Frankfurt am Main: Suhrkamp, 2000), S. 320.

44 Bdk. Axel Honneth, Umverteilung als, S. 154. 
bahwa setiap subjek selalu mengharapkan pengakuan akan tuntutan identitas dari masyarakat. ${ }^{45}$

Dengan demikian ketegangan afeksi yang diderita oleh individu hanya mungkin diatasi lewat mekanisme perlawanan politis. Pengalaman kekerasan tidak bersifat individual. Ia mempertemukan para korban sebagai sebuah kelompok kolektif yang bersama-sama berjuang memperlebar dimensi diri yang harus mendapat pengakuan. Dengan cara ini psikologi moral dapat membantu melahirkan struktur atau gramatika konflik sosial. Langkah penghubung antara realitas penderitaan dan motivasi untuk tindakan emansipatoris terletak pada pengetahuan (episteme) akan situasi konkret yang harus diperoleh dari perasaan (Gefühl) penindasan. Perasaan pendindasan ini memberikan informasi kognitif tentang situasi sosial kepada korban. ${ }^{46}$ Jadi bukan perasaan penindasan melainkan informasi mendorong diskursus tentang perubahan sosial. Kognisi, demikian Honneth, merupakan prasyarat bagi rekognisi.

\section{ETIKA RESIPROSITAS PRIMER}

Uraian tentang teori Honneth telah menghantar kita kepada pemahaman bahwa aktus pengakuan mengandung pengertian resiprositas jika secara normatif aktus tersebut harus menciptakan horison yang menjamin norma pengakuan. Pertanyaan yang masih tersisa ialah apakah aktus pengakuan nilai tersebut berkaitan dengan aktus kognitif atau berhubungan dengan praksis nonkognitif yang mendahuluinya. Atau dirumuskan secara lain, apakah pengakuan secara konstitutif mengandaikan pengetahuan ataukah secara logis keduanya harus dipisahkan. Honneth bergelut dengan pertanyaan ini dalam perkembangan teorinya dan membandingkannya dengan pandangan Sartre tentang proses pembendaan (Verdinglichung) atas dan oleh yang lain. ${ }^{47}$

45 Bdk. ibid., S. 155.

46 Bdk. Axel Honneth, Kampf um, S. 219.

47 Bdk. Axel Honneth, "Erkennen und Anerkennen. Zu Sartres Theorie über die Intersubjektivität," in Unsichtbarkeit, S. 17. 
22 Pluralitas dan Konsep Pengakuan Intersubjektifdalam Pemikiran Axel Honneth (Otto Gusti Madung)

Honneth mengembangkan teori yang memberikan prioritas atas pengakuan berhadapan dengan pengetahuan. Sebagai basis empiris atas tesis prioritas pengakuan, Honneth menggunakan hasil penelitian empiris atas psikologi bayi. Dalam penelitian tersebut diamati mimik dan gestur tubuh dalam relasi antara ibu dan bayinya. Psikologi perkembangan menafsir pengamatan-pengamatan ini sebagai bukti pentingnya orang dekat dalam memberi orientasi tindakan dan perasaan bagi sang bayi. Untuk mendapatkan pengalaman tentang dirinya dan batas-batas dunianya, anak kecil membutuhkan interaksi dengan yang lain. Dalam interaksi tersebut ia mengalami pantulan cermin perilakunya dan reaksi dari yang lain atas perilakunya itu. Teori tentang relasi masa awal kanak-kanak yang berorientasi harmoni ini bertolak dari kebutuhan primer akan kontak sosial yang muncul dalam interaksi-interaksi sangat awal masa kanak-kanak sebagai komunikasi timbal-balik nonverbal.

Lewat tindakan-tindakan ekspresionistis ini para pelaku interaksi menunjukkan kesediaan berkomunikasi, kedekatan emosional dan empati. Di antara pelbagai bentuk mimik dan gestur tubuh berbeda yang mengungkapkan kecocokan afeksi dan perhatian, Honneth menonjolkan sejumlah signal yang mengungkapkan kedekatan dan kasih terhadap anak. Secara psikologis hal tersebut memampukan sang bayi untuk merasakan bahwa dia dilindungi. Dengan demikian anak mulai mengembangkan bentuk-bentuk awal reaksi sosial. ${ }^{48}$

Semua tindakan ekspresif di atas memiliki pendasaran moral karena Honneth menganggapnya sebagai "metatindakan" (Metahandlung). ${ }^{49}$ Metatindakan merupakan indikasi bahwa referensi positif terhadap yang lain yang berkaitan dengan tindakan-tindakan tersebut juga di masa depan dapat diharapkan dari sang anak. Secara performatif tindakan itu menunjukkan bahwa sang aktor memiliki kewajiban moral tertentu. Bentuk-bentuk senyum dan kemesrahan membuka jalan menuju masa depan di mana perilaku yang baik diharapkan. Ketika dengan

48 Bdk. Ibid.

49 Ibid., S. 21. 
cara ini orang menyatakan respek terhadap yang lain, pada saat itu juga cinta diri (Selbstliebe) dalam bahasa Kant dibatalkan. Subjek yang mengakui mengalami proses desentralisasi ketika subjek mengakui yang lain sebagai otoritas moral. Di sini kelihatan sebuah ambivalensi, karena menurut Kant sumber tuntutan moral bukan yang lain konkret tapi hukum yang membatasi cinta diri (Selbstliebe).

Menurut Honneth pemahaman kognitif atas yang lain sudah kehilangan primatnya dan pengakuan selalu mendahului pengetahuan. Identifikasi kognitif atas yang lain sesungguhnya hanya mengungkapkan "hal khusus proses netralisasi dari pengakuan yang asali" (den Sonderfall der Neutralisierung einer ursprünglichen Anerkennung).$^{50}$ Jika kita mengikuti perkembangan konsep pengakuan Honneth, pengakuan semakin mendapat peran yang lebih fundamental. Dari interaksi variabel sosial dan historis dalam Kampf um Anerkennung menuju persepsi normatif yang mendahului pengetahuan dalam Unsichtbarkeit, lalu teori pengakuan kemudian dikembangkan sebagai relasi afirmatif substansial terhadap dunia dan yang lain. Pengertian terakhir dari konsep pengakuan memberikan penjelasan tentang proses pembendaan (Verdinglichung) dalam relasi sosial.

Pemahaman Honneth yang terakhir tentang pengakuan bertujuan untuk menunjukkan pengakuan sebagai sikap yang mendahului pendekatan kognitif terhadap dunia. Pemahaman ini diberi landasan teoretis baru. Sebagai dasar reformulasi konsep materialistis "Verdinglichung" dikemukakan bentuk-bentuk "lupa akan pengakuan" (Anerkennungsvergessenheit). Lupa akan pengakuan terungkap dalam fenomen di mana subjek lupa atau dibuat lupa (karena faktor sosial) bahwa pendekatan primer terhadap dunia dan yang lain tidak bertumpu pada pendekatan objektif, kognitif proposisional atau penguasaan atas alam (Naturbeherrschend), melainkan sikap mengakui dan apresiatif. Dalam relasi manusia terhadap dunia dan dirinya sikap mengakui dan apresiatif mendahului sikap-sikap lain baik secara genetis pun kate-

50 Ibid., S. 27. 
24 Pluralitas dan Konsep Pengakuan Intersubjektif dalam Pemikiran Axel Honneth (Otto Gusti Madung)

gorial. ${ }^{51}$ Konsep pengakuan dijelaskan secara ontogenetis. Konsep Heidegger tentang keprihatinan yang menguak dunia (Welterschließende Sorge) dan kritik John Dwey atas model penonton (Zuschauermodell) dalam ilmu pengetahuan ditafsir sebagai petunjuk bahwa pribadi manusia pertama-tama berada dalam situasi di mana dia harus bersikap, dan bukannya dalam dunia fakta-fakta di mana dia ditempatkan. Hal mendasar yang menyebabkan perubahan paradigma Honneth menuju paradigma eksistensial adalah distingsi Heideggerian antara keberadaan benda-benda (Vorhandenheit der Dinge) untuk pengetahuan dan kehadirannya (Zuhandenheit) untuk eksistensi duniawi kita. Distingsi ini membentuk pemahaman Honneth tentang konsep pengakuan dan menempatkan relasi antara pengakuan dan pengetahuan pada tataran yang baru. Bagi Honneth, pengakuan adalah apa yang Heidegger namakan "Eingelassensein in bereits wertbesetzte Weltbezüge"-"membiarkan diri masuk ke dalam relasi dunia yang sudah selalu sarat nilai." 52 Pengakuan adalah keterlibatan atau empati afektif dan eksistensial dalam hidup yang lain. ${ }^{53} \mathrm{Di}$ sini tampak jelas bahwa konsep pengakuan dalam pengertian Honneth bergeser dari struktur interaksi yang dianalisis di ranah sosial menuju sebuah pengakuan primer yang mengandung "momen keterbukaan bebas, pengabdian dan cinta." 54

\section{MENILAI KOGNITIVISME, AUTENTISITAS, DAN TELEOLOGI}

Dibandingkan dengan teori pengakuan interkultural, paradigma intersubjektif menunjukkan sejumlah kemajuan berarti. Tuntutan pendasaran moral antropologi dan psikologi mengatasi penyempitan konsep pengakuan pada tataran kultural semata. Juga kerangka sistema-tisnya yang mencakupi tiga tatanan pengakuan memberi pendasaran bagi momen normatif yang tidak dijumpai dalam paradigma interkultural.

51 Bdk. Axel Honneth, Verdinglichung. Eine anerkennungstheoretische Studie (Frankfurt am Main: Suhrkamp, 2005),S. 39.

52 Ibid., S. 51.

53 Bdk. ibid.

54 Ibid. 
Paradigma intersubjektif menggunakan pendekatan interdisipliner dan bersedia belajar serta dikritik oleh ilmu-ilmu sosial. Di samping beberapa keunggulan juga dijumpai sejumlah kelemahan dari pendekatan ini yang dirumuskan dengan judul kognitivisme, autentisitas dan teleologi.

Pertama, dalam menjawab pertanyaan entah pengakuan merupakan sebuah hasil pengetahuan atau sesuatu yang lain, teori Honneth mengalami perkembangan yang luar biasa. Jika dalam Kampf um Anerkennung tafsiran atas situasi empiris memberikan informasi apakah seseorang layak mendapat pengakuan, ${ }^{55}$ maka dalam perkembangan teori lebih lanjut pengetahuan dipandang sebagai salah satu model pengakuan. ${ }^{56}$ Namun pada tataran formasi teori ini masih terdapat kesenjangan yang tak terjembatani antara aspek kognitif dan normatif konsep pengakuan. Sebab mendasarnya terletak pada pengertian konsep pengakuan itu sendiri. Pengakuan harus menunjukkan aktus ekspresif di mana pengetahuan atau seorang pribadi mendapatkan makna dukungan positif. ${ }^{57}$ Tesis tentang prioritas pengakuan berhadapan dengan pengetahuan bertentangan dengan pembentukan nilai-nilai moral atas dasar pemahaman kognitif. Persoalan ini diselesaikan oleh Axel Honneth lewat pergeseran paradigma menuju paradigma eksistensialis dalam karya Verdinglichung. Dalam karya ini Honneth menjadikan modus pengakuan sebagai sikap dasar terhadap dunia, yang lain dan diri sendiri. Pengetahuan dan pengakuan dianggap setara. Keterbukaan fundamental terhadap yang lain memunculkan persoalan baru lain, yakni apa yang menjadi dasar rasional tuntutan normatif untuk mengakui yang lain. Sebab jika pengakuan dipandang sebagai eksistensi afirmatif kita di tengah dunia (affirmatives In-der-Welt-sein), maka memberikan pengakuan tidak dapat dikatakan benar, baik atau diwajibkan secara etis. Pengakuan merupakan sebuah faktum dan bukan tujuan normatif.

55 Bdk. Axel Honneth, Kampf um, S. 182.

56 Bdk. Axel Honneth, Unsichtbarkeit, S. 27.

57 Bdk. ibid., S. 15. 
Kedua, ketidakjelasan teori pengakuan Honneth dalam menyelesaikan persoalan relasi antara pengetahuan dan pengakuan disebabkan konsep autentisitasnya. Tujuan projek teoretis Honneth tentang intersubjektivitas dirumuskan sejak awal yakni perwujudan diri (Selbstverwirklichung) ${ }^{58}$ atau relasi yang integral dengan diri (ungebrochenes Selbstverhältnis). ${ }^{59}$ Yang lain tak lebih dari instrumen menuju diri yang autentik. Dalam paradigma intersubjektif yang lain sebagai yang lain tidak mungkin dapat dicapai. Di sini menjadi tidak jelas bagaimana menghubungkan sebuah teori yang di satu sisi peka terhadap fenomen pelecehan dan penindasan terhadap yang lain, namun di sisi lain bekerja dengan konsep substansial tentang relasi diri yang integral. ${ }^{60}$

Ketiga, projek teoretis Honneth berpijak pada struktur teleologis. Alasannya, pengandaian tentang struktur validitas normatif dan harapan akan kemajuan moral memungkinkan teori pengakuan intersubjektif memberikan penilaian atas kendala atau persoalan masing-masing tatanan pengakuan. Di sini muncul ambivalensi karena dalam diskusi tentang teorinya Honneth menunjukkan sikap terbuka. Karena itu belum pasti apakah konsep Sittlichkeit Hegel atau dalam bahasa Honneth "Reich der Gründe" (kerajaan penalaran-penalaran) harus dipahami secara material atau instrumental. Itu berarti bahwa entah konsep Sittlichkeit harus dipikirkan sebagai tujuan akhir perkembangan moral yang menjadi takaran dalam mengukur kemajuan ataukah Sittlichkeit hanya menyediakan syarat-syarat di dalamnya individualitas dan inklusi dapat berkembang tanpa harus menetapkan arah perkembangan tersebut.

\section{PENUTUP}

Konsep pengakuan intersubjektif coba memberikan solusi atas kegagalan yang ditinggalkan oleh liberalisme. Dengan menggunakan kerangka kritik Hegel atas formalisme filsafat moral dan hukum Kant,

58 Bdk. Axel Honneth, Umverteilung als, S. 206.

59 Bdk. Axel Honneth, Kampf um, S. 196.

60 Bdk. Stephan Gosepath, Gleiche Gerechtigkeit. Grundlagen eines liberalen Egalitarianismus (Frankfurt am Main: Suhrkamp, 2004), S. 102. 
Honneth memperluas jangkauan politik dari subjek hukum semata menuju seluruh pribadi (persona) manusia. Pendekatan pengakuan intersubjektif mengatasi konsep pengakuan interkultural seperti diperkenalkan oleh Charles Taylor karena dalam paradigma intersubjektif pengakuan sudah dilihat dalam pelbagai tingkatan interaksi antarmanusia yakni tataran cinta, hukum dan solidaritas. Dengan itu Honneth dapat menjelaskan kemajuan evolusi moral dan hukum sekaligus.

Meskipun demikian, konsep pengakuan intersubjektif Honneth gagal mengkonstruksikan sebuah identitas kolektif yang toleran karena ia masih terjebak dalam teleologi dan terobsesi dengan autentisitas. Tujuan (telos) dari pengakuan akan yang lain adalah perwujudan diri yang autentik. Dalam paradigma berpikir ini yang lain tak lebih dari instrumen untuk perwujudan diri. Pengakuan yang lain sebagai yang lain tak mungkin terwujud. Patologi autentisitas mempersulit formasi identitas kolektif dalam sebuah masyarakat multikultural. Intoleransi dan fundamentalisme kultural sering berakar pada obsesi menjaga kemurnian atau autentisitas identitas sendiri. Dalam kenyataan sesungguhnya identitas entah personal atau kolektif selalu terbangun dari ketegangan antara relasi sosial dan proses individualisasi. Secara politis hal ini berarti bahwa setiap tatanan demokratis selalu membutuhkan pandangan kolektif tentang komunitas. Sebab sebuah tatanan demokratis tidak diisi oleh individu-individu atomistik tanpa relasi sosial. Sebuah proses demokrasi selalu bergerak dalam sebuah masyarakat yang ditandai dengan relasirelasi sosial dan pelbagai proses formasi komunitas yang kompleks. Demokrasi dibangun di atas identitas kolektif yang formal dan rapuh. Identitas kolektif tak pernah selesai, melainkan selalu berada dalam proses menjadi diri dan menemukan diri secara baru.

\section{DAFTAR RUJUKAN}

Bauböck, Rainer. "Multiculturalism." In Routledge Encyclopedia of Social Theory, eds. Austin Harrington, Barbara Marshal, Hans-Peter Müller. London/New York, 2006, pp. 382-384.

Bourdieu, Pierre. Die feinen Unterschiede. Kritik der gesellschaftlichen Urteilskraft. Frankfurt am Main: uhrkamp, 1997. 
28 Pluralitas dan Konsep Pengakuan Intersubjektif dalam Pemikiran Axel Honneth (Otto Gusti Madung)

Emcke, Carolin. Kollektive Identitäten. Frankfurt am Main: Suhrkamp, 2000.

F. Klemme, Heiner, Manfred Kühn, Dieter Schönecker (Hg). Moralische Motivation. Kant und die Alternativen. Hamburg, 2006.

Gerhard, Volker. "Menschheit in meiner Person. Expose zu einer Theorie exemplariischen Handelns." Jb Recht Ethik 14 (2006): 215-224.

Gosepath, Stephan. Gleiche Gerechtigkeit. Grundlagen eines liberalen Egalitarianismus. Frankfurt am Main: Suhrkamp, 2004.

Hegel, Georg Wilhelm Friedrich. System der Sittlichkeit. Hamburg: Meiner Verlag,1967.

Hollinger, David. Postethnic America: Beyond Multiculturalism. New York: Basic Books, 2006.

Honneth, Axel. Kampf um Anerkennung. Zur moralischen Grammatik sozialer Konflikte. Frankfurt am Main: Suhrkamp, 1994. . Unsichtbarkeit. Stationen einer Theorie der Intersubjektivität. Frankfurt am Main: Suhrkamp, 2003.

. “Umverteilung als Anerkennung. Eine Erwiderung auf Nancy Fraser." In Umverteilung oder Anerkennung? Eine politischphilosophische Kontroverse, Hrsg. Nancy Fraser, Axel Honneth. Frankfurt am Main: Suhrkamp, 2003.

. Verdinglichung. Eine anerkennungstheoretische Studie. Frankfurt am Main: Suhrkamp, 2005.

Kaloianov, Radostin. "Multikulturalismus und Kritik." Polylog. Zeitschrift für interkulturelles Philosophieren 24 (2010): 81-97.

Kant, Immanuel. Grundlegung zur Metaphysik der Sitten. hrsg. v. Karl Vorländer. Hamburg: Meiner Verlag, 1994.

. Kritik der praktischen Vernunft. hrsg. v. Karl Vorländer. Hamburg: Meiner Verlag, 1990.

. Metaphysik der Sitten. hrsg. v. Bernd Ludwig. Hamburg: Meiner Verlag, 1990.

Kymlicka, Will. Multicultural Odysseys: Navigating the New International Politics of Diversity. Oxford: University Press, 2007.

Magnis-Suseno, Franz. Pijar-Pijar Filsafat. Yogyakarta: Kanisius, 2005.

Nohlen, Dieter und Reiner-Olaf Schultze. Lexikon der Politikwissenschaft. Theorien, Methode, Begriffe. Bd. I: A-M. München: Verlag C.H. Beck, 2002. 
Spinner- Halev, Jeff. "Multiculturalism and Its Critics." In The Oxford Handbook of Political Theory, eds. John. S. Dryzek/Bonnie Honing/ Anne Phillips. Oxford: University Press, 2008, pp. 546-564.

Taylor, Charles. "Die Politik der Anerkennung." In Multikulturalismus und die Politik der Anerkennung, Hrsg. Charles Taylor. Frankfurt am Main: Suhrkamp, 2009, SS. 11-66.

Vertovec, Steven and Susanne Wesendorf. Migration and Cultural, Religious and Linguistic Diversity in Europe: An overview of Issues and Trends. Centre on Migration, Policy and Society. Working Paper No. 18. University of Oxford, 2005. 